\title{
Importance of Anthropometric Characteristics in Athletic Performance from the Perspective of Bangladeshi National Level Athletes' Performance and Body Type
}

\author{
Adhikari Anup ${ }^{1, *}$, Pervin Nahida ${ }^{2}$, Rumy Nazrul Islam², Ali Kitab ${ }^{3}$ \\ ${ }^{1}$ Anthropmetrica, Toronto, Canada \\ ${ }^{2}$ Bangladesh Institute of Sports (BKSP), Dhaka, Bangladesh \\ ${ }^{3}$ Bangladesh Athletic Federation, Dhaka, Bangladesh \\ *Corresponding author: dranupadhikari@yahoo.com
}

Received February 24, 2014; Revised March 08, 2014; Accepted March 11, 2014

\begin{abstract}
The significant role of anthropometric characteristics in sport performance besides other factors is well known. Requirement of specific physique for good performance in specific sports has been established in different studies. The athletic performance of Bangladesh is not that much well and that might be due to different physiological or psychological or skill level aspects. A physical and physiological study was conducted to find out the reason for poor performance of the Track and Field athletes as athletic performance was more dependent on physiological demands besides skill and techniques. Body composition, somatotype and $\mathrm{VO}_{2 \max }$ of twenty-eight national level athletes (15 male and 13 female) were studied at Bangladesh Institute of Sports (BKSP). Average height and weight of the female athletes of the present study were $157.6 \mathrm{~cm}( \pm 5.4)$ and $50.6 \mathrm{~kg}( \pm 4.5)$ respectively with an average age of $17.8 \mathrm{yr}( \pm 1.6)$. The stature ranged between $149.0 \mathrm{~cm}$ and $166.2 \mathrm{~cm}$ whereas that of body weight was between $44.0 \mathrm{~kg}$ and $60.3 \mathrm{~kg}$. Similarly their male counterparts possessed an average height of $171.2 \mathrm{~cm}$ (SD \pm 7.5 , range 157.4. $\mathrm{cm}-181.4 \mathrm{~cm}$ ) with an average body mass of $62.7 \mathrm{~kg}(\mathrm{SD} \pm 8.2$, range $47.2 \mathrm{~kg}-73.5 \mathrm{~kg})$. A slightly high body fat $\%$ of 18.4 (SD \pm 2.3 , range $14.1 \%-22.0 \%$ ) was observed for the female athletes whereas that of their male counterparts was $7.9 \%$ (SD \pm 1.5 , range $5.7 \%-11.3 \%$ ). Average balanced mesomorph with less mesomorph component was observed for the female athletes $(2.7 \pm 0.5-3.4 \pm 0.9-2.7 \pm 0.9)$ while that of their male counterparts was ectomorphic mesomorph with less mesomorph component (1.5 $\pm 0.4-4.0 \pm 1.1-3.0 \pm 1.1)$. Normal range of body fat\% was observed both in male and female athletes with slightly higher in females. An average $\mathrm{VO}_{2 \max }$ of $45.3 \mathrm{ml} \mathrm{kg}^{-1} \cdot \mathrm{min}^{-1}$ (SD \pm 6.6 , range 34.1-56.1) was observed for female athletes whereas that of their male counterparts was $59.1 \mathrm{ml} \cdot \mathrm{kg}^{-1} \cdot \mathrm{min}^{-1}$ (SD \pm 5.3 , range 50.3- 68.4). Anthropometric characteristics in terms of Somatotype of the Bangladeshi athletes were poor compare to Olympians and other international athletes though the physiological aspects in terms of $\mathrm{VO}_{2 \max }$ were more considerable compare to international athletes. Hence, poor performance of Bangladeshi athletics might be due to poor anthropometric characteristics which support the importance of Anthropometric characteristics in athletic performances.
\end{abstract}

Keywords: body composition, somatotype, athlete, bangladesh

Cite This Article: Adhikari Anup, Pervin Nahida, Rumy Nazrul Islam, and Ali Kitab, "Importance of Anthropometric Characteristics in Athletic Performance from the Perspective of Bangladeshi National Level Athletes' Performance and Body Type.” American Journal of Sports Science and Medicine, vol. 2, no. 4 (2014): 123-127. doi: 10.12691/ajssm-2-4-1.

\section{Introduction}

Body composition and somatotype of a sportsman has a significant role in sports performance besides other factors like physiological and physical fitness, psychological aspects, skills etc. Requirement of specific physique for good performance in sports had been supported by different studies [1]. Various studies had been attempted to relate performance level with body type and body composition [2,3,4,5,6]. Relationship between the leg length and performance level during running had been established by different studies $[5,6,7,8]$. Similarly, physiological aspects in terms of $\mathrm{VO}_{2 \max }$ had an important role in athletic performance which was revealed by different studies [9-16]. Track and Field games (except Long distance and Marathon running) required a moderate and good aerobic power $\left(\mathrm{VO}_{2 \max }\right)$ besides good anaerobic power and muscle strength. Especially in Throwing and Jumping events, need more muscle strength with good muscularity. The athletic performance of Bangladesh was 
very poor. There might be different reasons but poor physical structure might be one of them. Lack of anthropometric studies on Bangladeshi athletes could not establish the influence of anthropometric characteristics on their performance level. The present study was aimed to evaluate the anthropometric characteristics of the Bangladesh national athletic squad and establish the importance of anthropometric characteristics on performance level.

\section{Method}

\subsection{Subjects}

The national athletic squad came to Bangladesh Institutes of Sports (BKSP) campus for a month long training program. Twenty-eight national level athletes (15 male and 13 female) were tested for their body composition and somatotype as a part of their Physical and Physiological evaluation.

\subsection{Anthropometric Measurements}

Anthropometric measurements were measured on a same day for each player in same session to avoid technical error with a criterion anthropometrist accredited by ISAK [17]. Method described in the International Society for The Advancement of Kinathropometry manual [18] was followed. Stature was measured with an Anthropometric Rod (GPS) up to $1 \mathrm{~mm}$ and body mass was measured with an electronic weighing machine. Skin fold thickness were measured with a Harpenden Skinfold caliper. Anthropometric tape was used for measuring girth while sliding caliper was used to measure bone diameter.

\subsection{Somatotype}

Heath - Carter [19] method was followed for Somatotype rating. The following equations were uses for calculating somatotype.
Endomorphy $=-0.7182+0.1451 \times \sum \mathrm{SF}-0.00068 \times$ $\sum \mathrm{SF}^{2}+0.0000014 \times \sum \mathrm{SF}^{3}$ where $\sum \mathrm{SF}=$ (sum of triceps, subscapular and supraspinale skinfolds) multiplied by (170.18/height in $\mathrm{cm}$ ). This is called height-corrected endomorphy and is preferred method for calculating endomorphy)

Mesomorphy $=0.858 \times$ humerus breadth $+0.601 \times$ femur breadth $+0.188 \times$ corrected arm girth $+0.161 \times$ corrected calf girth - height $\times 0.131+4.5$

Three different equations are used to calculate ectomorphy according to the height -weight ratio (HWR):

If HWR is greater than or equal to 40.75 then, Ectomorphy $=0.732 \times \mathrm{HWR}-28.58$.

If HWR is less than 40.75 and greater than 38.25 then, Ectomorphy $=0.463 \times$ HWR -17.63 .

If HWR is equal to or less than 38.25 then, Ectomorphy $=0.1$

\subsection{Body Fat $\%$}

Durnin and Womersley [20] technique was followed for body density. Body fat \% was derived from the equation of Brozek et al [21].

\section{5. $\mathrm{VO}_{2 \max }$ (Maximum Oxygen Consumption Capacity)}

The Bruce maximal graded exercise test protocol [22] was followed to measure the $\mathrm{VO}_{2 \max }$. The subject ran on a Treadmill (LE 200, Viasys, German) with a initial speed of $1.7 \mathrm{mph}$ at $10 \%$ grade. The inclination of the Treadmill was increased by $2 \%$ after every $3 \mathrm{~min}$ interval. The speed was increased from $1.7 \mathrm{mph}$ to $2.5 \mathrm{mph}$, 3.4mph, $4.2 \mathrm{mph}$, $5.0 \mathrm{mph}$, and $5.5 \mathrm{mph}$ with an interval of $3 \mathrm{~min}$ at each stage upto exhaustion. RQ more than 1 also considered as a criteria for measuring $\mathrm{VO}_{2 \max }$. Expired gas was analyzed breath by breath technique with a metabolic analyzer (Oxycon Pro, Eric Jager, Viasys, Germany).

Table 1. Anthropometrical characteristics and $\mathrm{VO}_{2 \max }$ of Bangladeshi male national athletes

\begin{tabular}{|c|c|c|c|c|c|c|c|c|c|}
\hline \multirow[b]{2}{*}{ Players ID } & \multirow[b]{2}{*}{ Event } & \multirow[b]{2}{*}{ Age $(\mathrm{yr})$} & \multirow[b]{2}{*}{ Height (cm) } & \multirow[b]{2}{*}{ Weight (kg) } & \multirow[b]{2}{*}{ Fat $\%$} & \multicolumn{3}{|c|}{ Somatotype } & \multirow[b]{2}{*}{$\mathrm{VO}_{2 \max }\left(\mathrm{ml} . \mathrm{kg}^{-1} \mathrm{~min}^{-1}\right)$} \\
\hline & & & & & & Endo & Meso & Ecto & \\
\hline $01 \mathrm{MA}$ & Triple Jump & 32 & 168.5 & 54.7 & 10.1 & 1.2 & 3.3 & 3.9 & 68.4 \\
\hline $02 \mathrm{MB}$ & $100 \mathrm{~m}$ & 29 & 167.7 & 52.9 & 8 & 1.6 & 3.3 & 4.2 & 64.4 \\
\hline $03 \mathrm{MC}$ & $100 \mathrm{~m}$ & 26 & 170.9 & 55.3 & 5.8 & 1.1 & 3.2 & 4.3 & 68.0 \\
\hline $04 \mathrm{MD}$ & $100 \mathrm{~m}$ & 35 & 168.4 & 63.6 & 8 & 1.6 & 4.2 & 2.3 & 66.7 \\
\hline $05 \mathrm{ME}$ & Hurdles & 25 & 171.5 & 75.4 & 9.8 & 1.9 & 7 & 1.2 & 52.3 \\
\hline $06 \mathrm{MF}$ & $400 \mathrm{~m}$ & 26 & 160.6 & 59.2 & 6.9 & 1.5 & 4.9 & 1.6 & 50.3 \\
\hline $07 \mathrm{MG}$ & $400 \mathrm{~m}$ & 19 & 157.4 & 47.2 & 5.9 & 1.2 & 3.6 & 3.3 & 58.9 \\
\hline $08 \mathrm{MH}$ & Triple Jump & 22 & 162.7 & 60.1 & 11.3 & 2.4 & 5.1 & 1.9 & 59.3 \\
\hline $09 \mathrm{MI}$ & $100,200 \mathrm{~m}$ & 23 & 172.9 & 55.5 & 5.7 & 1.2 & 2.4 & 4.6 & 58.5 \\
\hline $10 \mathrm{MJ}$ & $100,200 \mathrm{~m}$ & 23 & 178.3 & 71.3 & 7.4 & 1.3 & 3.6 & 2.9 & 58.4 \\
\hline $11 \mathrm{MK}$ & Hurdles & 24 & 172.8 & 66.9 & 8.1 & 1.5 & 4.6 & 2.6 & 57.6 \\
\hline $12 \mathrm{ML}$ & Triple Jump & 23 & 181.4 & 70.2 & 7.7 & 1.3 & 4 & 3.7 & 55.6 \\
\hline $13 \mathrm{MM}$ & $100 \mathrm{~m}$ & 23 & 173.2 & 68.2 & 8 & 1.5 & 4.4 & 2.5 & 58.8 \\
\hline $14 \mathrm{MN}$ & $100 \mathrm{~m}$ & 22 & 175.3 & 66.5 & 8.6 & 1.6 & 4 & 3.1 & 56.5 \\
\hline $15 \mathrm{MO}$ & $100 \mathrm{~m}$ & 19 & 187 & 73.5 & 7 & 1.1 & 3.4 & 4.1 & 55.6 \\
\hline $16 \mathrm{MP}$ & $100 \mathrm{~m}$ & 20 & 169.6 & 63 & 8.2 & 2.5 & 5 & 2 & 56.0 \\
\hline mean & & 24.4 & 171.1 & 62.7 & 7.9 & 1.5 & 4.1 & 3.0 & 59.1 \\
\hline SD & & 4.4 & 7.5 & 8.2 & 1.5 & 0.4 & 1.1 & 1.1 & 5.3 \\
\hline
\end{tabular}


Table 2. Anthropometrical characteristics and $\mathrm{VO}_{2 \max }$ of Bangladeshi female national athletes

\begin{tabular}{|c|c|c|c|c|c|c|c|c|c|}
\hline \multirow{2}{*}{ Players ID } & \multirow{2}{*}{ Event } & \multirow{2}{*}{ Age (yr) } & \multirow{2}{*}{ Height (cm) } & \multirow{2}{*}{$\begin{array}{c}\text { Weight } \\
(\mathrm{kg})\end{array}$} & \multirow{2}{*}{ Fat $\%$} & \multicolumn{3}{|c|}{ Somatotype } & \multirow{2}{*}{$\mathrm{VO}_{2 \max }\left(\mathrm{ml} \cdot \mathrm{kg}^{-1} \min ^{-1}\right)$} \\
\hline & & & & & & Endo & Meso & Ecto & \\
\hline $01 \mathrm{FA}$ & High Jump & 16 & 166.2 & 53.7 & 22 & 3.2 & 2.2 & 3.7 & 34.1 \\
\hline $02 \mathrm{FB}$ & High Jump & 22 & 163.5 & 50.6 & 19.8 & 2.9 & 1.8 & 3.8 & 35.0 \\
\hline $03 \mathrm{FC}$ & Long Jump & 19 & 159.3 & 48.5 & 18.6 & 2.6 & 2.4 & 3.4 & 48.8 \\
\hline $04 \mathrm{FD}$ & Hurdles & 16 & 161.7 & 54.8 & 18 & 2.3 & 3.3 & 2.6 & 48.7 \\
\hline $05 \mathrm{FE}$ & $800 \mathrm{~m}$ & 17 & 162.5 & 51.3 & 19.2 & 2.7 & 3.4 & 3.5 & 52.5 \\
\hline $06 \mathrm{FF}$ & $400 \mathrm{~m}$ & 18 & 149 & 46.3 & 18.7 & 2.7 & 3.9 & 1.8 & 41.0 \\
\hline $07 \mathrm{FG}$ & $100,200 \mathrm{~m}$ & 16 & 150.3 & 47.6 & 16.8 & 2.4 & 4 & 1.8 & 42.3 \\
\hline $08 \mathrm{FH}$ & $800,1500 \mathrm{~m}$ & 18 & 155.9 & 45 & 14.1 & 1.7 & 3.3 & 3.5 & 56.1 \\
\hline $09 \mathrm{FI}$ & Throwing & 18 & 156.2 & 60.3 & 23 & 4 & 4.9 & 1 & 46.0 \\
\hline $10 \mathrm{FJ}$ & High Jump & 19 & 153 & 44 & 16.8 & 2.4 & 3.3 & 3.2 & 48.5 \\
\hline $11 \mathrm{FK}$ & $100,200 \mathrm{~m}$ & 17 & 152.9 & 51.2 & 17 & 2.7 & 4.4 & 1.6 & 48.5 \\
\hline $12 \mathrm{FL}$ & $100 \mathrm{~m}$ & 17 & 161.7 & 54.8 & 16.6 & 2.3 & 3.8 & 3 & 48.7 \\
\hline $13 \mathrm{FM}$ & $100 \mathrm{~m}$ & 18 & 156 & 49.3 & 18.5 & 2.7 & 3.2 & 2.6 & 39.1 \\
\hline mean & & 17.8 & 157.6 & 50.6 & 18.4 & 2.7 & 3.4 & 2.7 & 45.3 \\
\hline SD & & 1.6 & 5.4 & 4.5 & 2.3 & 0.5 & 0.9 & 0.9 & 6.6 \\
\hline
\end{tabular}

\section{Results}

Table 1 showed the anthropometrical characteristics and $\mathrm{VO}_{2 \max }$ of the male athletes whereas the Table 2 showed that of the female counterparts. The male athletes were $24.4 \mathrm{yr}$ old in average with a range between $19 \mathrm{yr}$ and 32 yr. The average stature obtained for these male Bangladeshi athletes was $171.1 \mathrm{~cm}( \pm 7.5)$ with a range between $157.4 \mathrm{~cm}$ and $181.4 \mathrm{~cm}$. The body weight of these male athletes varied from $47.2 \mathrm{~kg}$ to $72.5 \mathrm{~kg}$ with an average body weight of $62.7 \mathrm{~kg}$.

Table 2 showed the anthropometrical characteristics and $\mathrm{VO}_{2 \max }$ of the female counterparts. Most of the female athletes were very young with an average age of $17.8 \mathrm{yr}$ ( \pm 1.6) with a range between 16 yr and 22 yr. Their average height was $157.6 \mathrm{~cm}( \pm 5.4)$. The tallest girl of the group was $166.2 \mathrm{~cm}$ compare to the shortest stature of $149.0 \mathrm{~cm}$. Average body weight was comparatively low which was $50.6 \mathrm{~kg}$ with a standard deviation of 4.5 where the highest value was $60.3 \mathrm{~kg}$ and the lowest was $44 \mathrm{~kg}$.

A slightly high body fat $\%$ of 18.4 (SD \pm 2.3 , range $14.1 \%$ - 22.0\%) was observed for the female athletes whereas that of their male counterparts was $7.9 \%( \pm 1.5)$ with a range between $5.7 \%$ and $11.3 \%$. Poor muscularity with less mesomorph component were observed for most of the athletes while considering the male and female both. The female athletes were balanced mesomorph in average whereas the male athletes were ectomorphic mesomorh in average. The obtained components were 2.7-3.4-2.7 with a standard deviation of \pm 0.5-0.9-0.9 for endo-meso-ecto components for the female athletes whereas those of male athletes were 1.5-4.1-3.0 with a standard deviation of \pm 0.4-1.1-1.1.

Average $\mathrm{VO}_{2 \max }$ for the male athletes was $59.1 \mathrm{ml} . \mathrm{kg}^{-}$ ${ }^{1}$. mim $^{-1}$ with a range between 50.3 and 68.4. The standard deviation was $5.3 \mathrm{ml} \cdot \mathrm{kg}^{-1} \cdot \mathrm{min}^{-1}$. Similarly, that of their female counter parts was $45.3 \mathrm{ml} . \mathrm{kg}^{-1} \cdot \mathrm{mim}^{-1}$ with a range between 34.1 and 56.1 ( $\mathrm{SD} \pm 6.6 \mathrm{ml}$ ). In both cases the aerobic power in terms of $\mathrm{VO}_{2 \max }$ were moderate and in some cases they were in good category (Table 1 and Table 2).

\section{Discussion}

Physical characteristics of a sportsman has a tremendous influence on the performance level besides personal skill and mental ability and a range of studies had been done on sportsman about their morphological evaluation along with their performance related morphological issues [23-28]. These studies revealed that height can play a significant role in contributing to success in some sports by offering certain natural advantages. For those sports where this could be a contributing factor, height can be useful (although certainly not in all cases, and is not the only factor) since in general it affects the leverage between muscle volume and bones towards greater speed of movement and power, depending on overall build, fitness and individual ability. However, there can also be significant disadvantages posed by size and resultant mass that could prove to be a hindrance to success. But in Track and Field athletics, most of the events required a good height and weight for better performance [23-28].

In the present study, most of the female athletes were very young and some of them were under $19 \mathrm{yr}$ except one with 22 yr. But their male counterparts were more senior to them and all were more than $19 \mathrm{yr}$. The average height was comparatively less than their international counterparts but very close to average height of Bangladeshi women. Average height of Bangladeshi women was comparatively less. According to the recent study, the average Bangladeshi women possessed an average height of $147.9 \mathrm{~cm}$ with a standard deviation of 5.2 where the range was between $119.5-165.4 \mathrm{~cm}$ [29]. Similarly, the average height of Bangladeshi male squad was also less than their international counterparts but very similar to the average height of Bangladeshi male population [29].

Negative relationship between sports performance especially sprinting events and adiposity in terms of body Fat\% were revealed by different studies though some of the studies showed less relationship of body fat\% with endurance activity in term of maximum oxygen consumption [30,31,32]. However, a range between 3.3\% and 18.4 was reported for male athletes whereas that of the female was observed to be in between $8.4 \%$ and $28 \%$. These included Track and Field, Soccer, Basketball, Football, Ice Hockey, Body building, Wrestling,, CrossCountry skiing, Baseball, Tennis and Power lifting. However, Track and field athletes possessed as low as 
$3.3 \%$ body fat for the marathon runners whereas the male sprinters and discus throwers reported to be with a higher value of $16.4 \%$. Similarly, the female Pentatheletes reported to have lowest value of $11 \%$ whereas the Track and field jumpers and hurdlers were performing with $20.7 \%$ fat. Highest values were observed for the female Discus throwers and Shot-putters, which were 25\% and $28 \%$ respectively [33,34]. For the Bangladeshi female athletes, an average value of $18.4 \%$ was observed which seemed to be satisfactory when compare to their other international counterparts. The long distance runners possessed low value of $14.1 \%$ whereas that of jumping event players was $22 \%$. While the Bangladeshi male athletes were considered they possessed an average value of 7.9 percent. Sprinters possessed a low value of 5.7 in contrary to the 11.3 for the jumpers.

Body type in terms of somatotype is an important factor for enhancement of performance besides other factors, which has been supported by various studies [23,35,36,37]. Recent studies showed that body mass index (BMI), reflecting greater muscle mass rather than greater adiposity, is the important factor associated with best performance for the world-class sprinters. The study also revealed that in track and field athletes, the reciprocal ponderal index (RPI) was an important indicator of best performance with tall and lean body type. However the study supported the decade long hypothesis for encouraging the ectmorphic mesomorph body type for the of Track and Field athletes with higher reciprocal Ponderal index [38]. Other studies also showed that mesomorphic component was a dominant characteristic of somatotype for Track and Field athletes compare to other two components $[4,5,6,7,8,37,38]$.

Bangladeshi male athletes of the present study were ectomorphic-mesomorph in average with a endo-mesoecto components of 1.5-4.1-3.0 whereas the female athletes were balanced mesomorph with endo-meso-ecto components of 2.7-3.4-2.7. Most of the male athletes were very poor in muscularity, which were less than 4 . Only two of the whole squad possessed mesomorphic components more than 5. Similarly in female squad, most of the athletes were with less than 4.0 mesomorphic component whereas only three were more than 4.0 mesomorphic components. In both cases the mesomorphic components were very less indicating poor muscularity for the Bangladeshi athletes irrespective of gender. Bangladeshi male track and field athletes possess less mesomorph components while comparing with the average $5.0( \pm 0.9)$ mesomorph component of the Olympic athletes compiled by Carter [32]. The male Olympic athletes, compiled by Carter [32] possessed an average somatotype of 1.8- 5.0-3.0 with a standard deviation of \pm $0.5- \pm 0.9- \pm 0.8$. Interestingly, the average somatotype of the Bangladeshi male athletes were very similar with somatotype value observed for the neighboring Indian rural athletes which was 2.6-3.3-3.4 studies by Bhatnagar and Grewal [2]. Similar observations were also observed for the female track and field athletes too. The average somatotype for the female Track and Field athletes, compiled by Carter [32] for the 1968 and 1976 Olympics, were 2.8-3.7-3.2 which was higher than the average somatotype of Bangladeshi female athletes.

Maximum oxygen consumption capacity $\left(\mathrm{VO}_{2 \max }\right.$ is one of the most important characteristics for cardio-vascular fitness, especially for the long distance events in athletic field. In sprinting events and in Throwing \& Jumping events, anaerobic power is more dominant than aerobic power or $\mathrm{VO}_{2 \max }$ and require a moderate $\mathrm{VO}_{2 \max }$ rather than a high $\mathrm{VO}_{2 \max }[17,18,19,20,30,31,32]$. In the present study all the athletes were from sprinting events or from Throwing \& Jumping events and require a moderate level of $\mathrm{VO}_{2 \max }$. Both male and female athletes possessed a moderate value for $\mathrm{VO}_{2 \max }$ compared with international standard, which did not reflected in their sports performance.

The performance level of Track and Field events for Bangladesh was not good enough compare to other countries even when compare with South Asian athletes. Most of the athletes in Bangladesh are from low socioeconomic status. Only few athletes were from middleincome group. This poor socio economic status causes unavailability of proper nutrition required for the athletes' growth and development during their adolescent stage, absence of which hinder the growth and development of muscle along with other physical characteristics, though they had a moderate of high level of aerobic power sufficient for showing good performance in their own events which they did not. Thus, good performance in their own events might be hampered by their poor physical characteristics though they had a moderate to good aerobic power compare to international athletes. Hence, it could be concluded that anthropometrical characteristics were one of most influential factors in determining good athletic performances besides other physiological characteristics.

\section{References}

[1] Carter, J.E.L, Heath, B.H., Somatotyping - development and application. Cambridge, Cambridge University Press, 1990.

[2] Bhatnagar,. D.P., Grewal, R., A comparative study of rural athletes of four states of India, Brit. J. Sports Med., 18 (1): 34-37, 1984.

[3] Bayios, I.A., Bergeles, N.K., Apostolidis, N.G., Noustsos, K.S., Koskolou, M.D., Anthropometric, body composition and somatotype differences of Greek elite female basketball, volleyball and handball players, J. Sports Med Phys Fitness, 46 (2): 271-280, 2006.

[4] Artioli, G.G., Gualano, B., Franchini, E., Batista, R.N., Polacow, V.O., Jr. Lancha, A.H., Physiological, performance, and nutritional profile of the Brazilian Olympic Wushu (kung-fu) team, J Strength Cond Res, 23 (1): 20-25, 2009.

[5] Hagberg, J.M., Rankinen, T., Loos, R.J., Perusse, L., Roth, S.M., Wolfarth B., Bouchard, C., Advances in exercise, fitness, and performance genomics in 2010, Med. Sci. Sports Exerc., 43 (5): 743-752. 2011.

[6] Kim, J., Cho, H.C., Jung, H.S., J.D. Yoon, J.D., Influence of performance level on anaerobic power and body composition in elite male judoists, J Strength Cond Res, 25 (5): 1346-1354, 2011

[7] Kyriazis, T., Terzis, G., Karapatsos, G., Kavouras, S., Georgiadis, G., Body composition and performance in shot put athletes at preseason and at competition, Int J sports Physiolo Perform, 5 (3): 417-421, 2010.

[8] Potteiger, J.A., Smith, D.L., Maier, M.L., Foster, T.S., Relationship between body composition, leg strength, anaerobic power, and on-ice skating performance in division I men's hockey athletes, J Strength Cond Res, 24 (7): 1755-1762, 2010.

[9] Conley, D.L., Krahenbuhl, G.S., Running economy and distance running performance of highly trained athletes, Med. Sci. Sports. Exerc, 12: 357, 1980.

[10] Hoffman, J.R., Physiological Aspects of Sport Training and Performance, Champaign, IL, Human Kinetics, 25-26, 2002. 
[11] Brook, G.A., Fahey, T.D., Baldwin, K.M., Exercise Physiology: human Bioenergetics and its application, 4th ed, New York, McGraw-Hill, 2005.

[12] Astrond, P.O., Rodahl, K., Dahl, H.A., Stromme, S.B., Textbook of work physiology: Physiological basis of Exercise, 4th ed, Champaign, IL, human Kinetics, 2003.

[13] John, E. H., Guyton and Hall Textbook of Medical Physiology, 12th Ed., Saunders, 2012.

[14] Hagerman, F.C., Applied physiology of rowing, Sports Med. 1 (4) (4): 303-26, 1984.

[15] Bassett, D. R., Howley, E.T., Maximal oxygen uptake: "classical" versus "contemporary" viewpoints, Med Sci Sports Exerc, 29 (5): 591-603, 1997.

[16] Bassett D.R Jr. \& Howley E.T., Limiting factors for maximum oxygen uptake and determinants of endurance performance, Med Sci Sports Exerc. 32 (1): 70-84, 2000.

[17] ISAK, International Society for the Advancement of Kinanthropometry, 1986, www.isakonline.com

[18] ISAK manual, International standards for Anthropometric Assessment, edited by Michael Marfell-Jones, Tim Olds, Arthur Stewart and L.E. Lindsay Carter, Published by International Society for the Advancement of Kinanthropometry, 2012

[19] Heath, B.H., Carter, J.E.L, A modified somatotype method, American Journal of Physical Anthropology, 27: 57-74, 1967.

[20] Durnin, J.V.G.A., Womersly, J., Body fat assessed from total from total body density and its estimation from skinfold thicknesses. Brtish Journal Nutrition, 32: 77-79, 1974.

[21] Brozek. J., Grande, F., Anderson, J.T., Keys, A., Densitometric analysis of body composition: revision of some quantitative assumptions. Annals of the New York Academy of Sciences, 110: 113-140, 1963.

[22] Bruce, R.A., Kusumi, F., Hosmer, D., maximum oxygen intake and nomographic assessment of functional aerobic impairment in cardiovascular disease, American Heart Journal, 85: 546-562, 1973.

[23] Carter, J.E.L., Physical Structure of Olympic athletes, Part II, Kinanthropometry of Olympic Athletes, Ed Karger, Basel,1984.

[24] Sidhu, L.S., Kansal, D.K., Kanda, B.S., Anthropometric and roentgenogrammetric assessment of physique and body composition of athletes specialising in throwing events, J Sports Med Phys Fitness, 115 (3): 192-198, 1975.

[25] Novak, L.P., Bestit, C., Mellerowicz, H., Woodward, W.A., Maximal oxygen consumption, body composition and anthropometry of selected Olympic male athletes, J Sports Med Phys Fitness,18 (2): 139-151, 1978.
[26] Cureton, K.J., Sparling, P.B., Distance running performance and metabolic responses to running in men and women with excess weight experimentally equated, Med Sci Sports Exerc, 12 (4): 288-294, 1980.

[27] Bhatnagar, D.P., Some morphological measures in athletes, volleyball and Kabbadi players of rural areas of Madhya Pradesh, J Sports Med Phys Fitness, 20 (1): 102-109, 1980.

[28] Slaughter, M.H., Lohman, T.G., An objective method for measurement of musculo-skeletal size to characterize body physique with application to the athletic population, Med Sci Sports Exerc, 12 (3): 170-174, 1980.

[29] Hosegood, V., Oona, R., Campbell Body mass index, height, weight, arm circumference, and mortality in rural Bangladeshi women: a 19-y longitudinal study, American Journal of Clinical Nutrition, 77 (2): 341-347, 2003.

[30] Goran, M., Fields, D.A., Hunter, G.R., Herd, S.L., Weinsier, R.L., Total body fat does not influence maximal aerobic capacity, International Journal of Obesity, 24, 841-848, 2000.

[31] Sporis, G., Jukic, I., Bok, D., Vuleta, D. Jr., Harasin, D., Impact of body composition on performance in fitness tests among personnel of the Croatian navy, Coll Anthropol, 35 (2): 335-339, 2011.

[32] McArdle, A.D., Katch, F.I., Katch, V.L., Exercise Physiology, 5th Ed, Lippincot Williams \& Wilkins, 794-819, 2001.

[33] Franchini, E., Del, Vecchio, F.B., Matsushigne, K.A., Artioli, G.G., Physiological profiles of elite judo athletes, Sports Med, 41 (2): 147-166, 2011.

[34] Aitken, A., Clarke, P.T., Brown, I.J., Kay, D., The relationship between body shape (somatotype) and body satisfaction (cathexis) in male physical educators, Scottish Journal of Physical Education, 8 (3): 30-33, 1980.

[35] Bale, P., Colley, E., Mayhew, J., Size and somatotype correlates of strength and physiological performance in adult male students, Australian Journal of Science and Medicine in Sport, 16: 2-6,1984

[36] Watts, A.S., Coleman, I., Nevill, A., The changing shape characteristics associated with success in world-class sprinters, J Sports Sci, 14: 701-718, 2011.

[37] Vucetic, V., Matkovi, B.R., Sentija, D., Morphological differences of elite Croatian track-and-field athletes. Coll Anthropol, 32 (3): 863-868, 2008.

[38] Nande, P., Mudafale, V., Vali, S., Anthropometric profile of female and male players engaged in different sports disciplines, The Internet Journal of Nutrition and Wellness, 8 (1), 2009, available at http://yester.ispub.com/journal/the-internet-journal-ofnutrition-and-wellness/volume-8-number-1. 